\title{
Heterogeneous Vascular Bed Responses to Pulmonary Titanium Dioxide Nanoparticle Exposure
}

\author{
Alaeddin B. Abukabda', Phoebe A. Stapleton ${ }^{2}$, Carroll R. McBride ${ }^{1}$, Jinghai $\mathrm{Yi}^{1}$ and \\ Timothy R. Nurkiewicz ${ }^{1 *}$ \\ 'Department of Physiology and Pharmacology, West Virginia University School of Medicine, Morgantown, WV, USA, \\ ${ }^{2}$ Department of Pharmacology and Toxicology, Rutgers University, Piscataway, NJ, USA
}

OPEN ACCESS

Edited by:

Junjie Xiao,

Shanghai University, China

Reviewed by:

Carine Michiels,

Université de Namur, Belgium Kenneth Walsh,

Boston University School

of Medicine, USA

*Correspondence:

Timothy R. Nurkiewicz

trnurkiewicz@hsc.wvu.edu

Specialty section:

This article was submitted to General Cardiovascular Medicine,

a section of the journal Frontiers in Cardiovascular Medicine

Received: 15 February 2017 Accepted: 01 May 2017

Published: 24 May 2017

Citation:

Abukabda AB, Stapleton PA, McBride CR, Yi J and Nurkiewicz TR (2017) Heterogeneous Vascular Bed

Responses to Pulmonary Titanium Dioxide Nanoparticle Exposure.

Front. Cardiovasc. Med. 4:33. doi: 10.3389/fcvm.2017.00033
A growing body of research links engineered nanomaterial (ENM) exposure to adverse cardiovascular endpoints. The purpose of this study was to evaluate the impact of ENM exposure on vascular reactivity in discrete segments so that we may determine the most sensitive levels of the vasculature where these negative cardiovascular effects are manifest. We hypothesized that acute nano- $\mathrm{TiO}_{2}$ exposure differentially affects reactivity with a more robust impairment in the microcirculation. Sprague-Dawley rats (8-10 weeks) were exposed to nano- $\mathrm{TiO}_{2}$ via intratracheal instillation $(20,100$, or $200 \mu \mathrm{g}$ suspended per $250 \mu \mathrm{L}$ of vehicle) $24 \mathrm{~h}$ prior to vascular assessments. A serial assessment across distinct compartments of the vascular tree was then conducted. Wire myography was used to evaluate macrovascular active tension generation specifically in the thoracic aorta, the femoral artery, and third-order mesenteric arterioles. Pressure myography was used to determine vascular reactivity in fourth- and fifth-order mesenteric arterioles. Vessels were treated with phenylephrine, acetylcholine (ACh), and sodium nitroprusside. $\mathrm{Nano}-\mathrm{TiO}_{2}$ exposure decreased endothelium-dependent relaxation in the thoracic aorta and femoral arteries assessed via ACh by $53.96 \pm 11.6$ and $25.08 \pm 6.36 \%$, respectively. Relaxation of third-order mesenteric arterioles was impaired by 100 and $20 \mu \mathrm{g}$ nano$\mathrm{TiO}_{2}$ exposures with mean reductions of $50.12 \pm 8.7$ and $68.28 \pm 8.7 \%$. Cholinergic reactivity of fourth- and fifth-order mesenteric arterioles was negatively affected by nano- $\mathrm{TiO}_{2}$ with diminished dilations of $82.86 \pm 12.6 \%$ after exposure to $200 \mu \mathrm{g}$ nano$\mathrm{TiO}_{2}, 42.6 \pm 12.6 \%$ after $100 \mu \mathrm{g}$ nano- $\mathrm{TiO}_{2}$, and $49.4 \pm 12.6 \%$ after $20 \mu \mathrm{g}$ nano- $\mathrm{TiO}_{2}$. Endothelium-independent relaxation was impaired in the thoracic aorta by $34.05 \pm 25 \%$ induced by exposure to $200 \mu \mathrm{g}$ nano- $\mathrm{TiO}_{2}$ and a reduction in response of $49.31 \pm 25 \%$ caused by $100 \mu \mathrm{g}$ nano- $\mathrm{TiO}_{2}$. Femoral artery response was reduced by $18 \pm 5 \%$, while third-order mesenteric arterioles were negatively affected by $20 \mu \mathrm{g}$ nano- $\mathrm{TiO}_{2}$ with a mean decrease in response of $38.37 \pm 10 \%$. This is the first study to directly compare the differential effect of ENM exposure on discrete anatomical segments of the vascular tree. Pulmonary ENM exposure produced macrovascular and microvascular dysfunction resulting in impaired responses to endothelium-dependent, endothelium-independent, and adrenergic agonists with a more robust dysfunction at the microvascular level. These results provide additional evidence of an endothelium-dependent and endotheliumindependent impairment in vascular reactivity.

Keywords: engineered nanomaterials, titanium dioxide, cardiovascular system, microcirculation, endothelium 


\section{INTRODUCTION}

Engineered nanomaterials (ENMs) are most commonly defined as a homogeneous mixture of anthropogenic materials possessing at least one dimension less than or equal to $100 \mathrm{~nm}$ (1) and have historically been used in inhalation toxicology research as surrogates for environmental air pollution studies to model ultrafine particulate matter exposures $(2,3)$. The continued development of novel ENM with diverse physicochemical properties represents a growing economic sector. Presently, the nanotechnology industry is one of the fastest growing markets with an estimated projected worth of $\$ 75.8$ billion by 2020 (4). This increased prevalence of ENM not only continues concerns over their safety and the potential adverse health outcomes that may occur as a result of prolonged, unmitigated exposure but also warrants more thorough toxicological assessments of their potential deleterious systemic effects.

Titanium dioxide (nano- $\mathrm{TiO}_{2}$ ) is among the most widely used nanomaterials, and its optical properties allow it to be used in consumer products such as topical sunscreens and cosmetics, as well as industrial components including paints (5). It is used commonly as a photocatalyst, catalyst carrier, heat stabilizer, and food additive (6). Nano- $\mathrm{TiO}_{2}$ may also be used as a drug carrier in nanomedicine (7).

Pulmonary nano- $\mathrm{TiO}_{2}$ exposure has been associated with systemic inflammation in vivo (8-10), with dose dependent overt inflammation characterized by a marked increase in proinflammatory mediators and lung toxicity $(10,11)$.

The circulatory system can be grossly divided into two major components based on structure and location: the macrocirculation and the microcirculation. The macrocirculation refers to the conduit arteries and veins, which connect the heart with the systemic organs and also function as pressure and blood reservoirs, respectively. The microcirculation is a broad term encompassing all the vascular tissue within a specific organ, including arterioles, the capillary network, and venules (12). Its fundamental function is the maintenance of an ideal internal environment for the controlled exchange of nutrients and metabolic waste with the adjacent tissues. For this study, conduit arteries and arterioles were chosen because they are major hemodynamic regulators and key players in the maintenance of blood pressure, flow distribution, and tissue perfusion $(13,14)$.

The endothelium is a regulator of vascular homeostasis and is extremely sensitive to changes in blood composition and hemodynamics (15). Consisting of a monolayer of cells that functions as a physical barrier for the exchange of materials between blood and tissues (16), it is also responsible for the secretion of a variety of molecules, including prostacyclins (17), clotting factors (18), and ectonucleotidases (19) that are important for the regulation of blood coagulation and platelet function. Endothelial cells also coordinate the recruitment of immune cells to sites of injury or infection via both the production and release of cytokines (20) and the expression of specific cell adhesion molecules on their apical surface that mediate leukocyte attachment and extravasation (21-24). While common to all vascular segments, endothelial cells show significant morphological and functional heterogeneity throughout the vasculature, between different organs, and between neighboring endothelial cells of the same organ and blood vessel type (25). These phenotypic differences may account for the differential and vascular bed-specific responses of endothelial cells to specific toxicants.

We have previously established that nano- $\mathrm{TiO}_{2}$ exposure is associated with systemic vascular dysfunction (26-28). However, the relative sensitivity to ENM of each vascular segment is not known. Therefore, the aim of this study is to assess the effects of three occupationally relevant nano- $\mathrm{TiO}_{2}$ concentrations on both the macrocirculation and the microcirculation from a functional perspective via wire and pressure myography. One hundred micrograms of nano- $\mathrm{TiO}_{2}$ were selected based on previous work conducted by our group (2). In addition, 200 and $20 \mu \mathrm{g}$ were chosen for this study to identify the maximum and minimum observed dose responses. The most sensitive vascular level to nano- $\mathrm{TiO}_{2}$ exposure was subsequently determined. On the basis of our previous results, we hypothesize that nano- $\mathrm{TiO}_{2}$ exposure impairs endothelium-dependent responsiveness and that this effect is more pronounced in the microcirculation.

\section{MATERIALS AND METHODS}

\section{Nanomaterial Characterization}

Nano- $\mathrm{TiO}_{2} \mathrm{P} 25$ powder, obtained from Evonik (Aeroxide $\mathrm{TiO}_{2}$, Parsippany, NJ, USA), has previously been shown to be a mixture composed primarily of anatase $(80 \%)$ and rutile $(20 \%) \mathrm{TiO}_{2}$, with a primary particle size of $21 \mathrm{~nm}$ and a surface area of $48.08 \mathrm{~m}^{2} \mathrm{~g}^{-1}$ $(2,29,30)$.

\section{Experimental Animals and Exposure}

Male (8-10 weeks) Sprague-Dawley rats were purchased from Hilltop Laboratories (Scottdale, PA, USA) and housed at WVU with 12:12 h light-dark cycle and regulated temperature. Rats were allowed ad libitum access to food and water. All procedures were approved by the Institutional Animal Care and Use Committee of West Virginia University and abide by the standards set forth in the "Guide for Care and Use of Laboratory Animals" of the National Research Council of the National Academies.

Bolus doses of nano- $\mathrm{TiO}_{2}(20,100$, and $200 \mu \mathrm{g})$ were suspended in $250 \mu \mathrm{L}$ of vehicle (normosol and $5 \%$ fetal bovine serum) for intratracheal instillation (IT) $24 \mathrm{~h}$ prior to experimentation. Nano- $\mathrm{TiO}_{2}$ suspensions were sonicated over ice for $1 \mathrm{~min}$ to ensure increased dispersion. Sprague-Dawley rats were anesthetized using 5\% isoflurane and placed on a mounting stand for IT with $200 \mu \mathrm{L}$ of vehicle (negative control) or the nano- $\mathrm{TiO}_{2}$ suspensions.

\section{Mean Arterial Pressure (MAP) Acquisition}

Rats were anesthetized with isoflurane gas (5\% induction, $3-3.5 \%$ maintenance) and placed on a heating pad to maintain a $37^{\circ} \mathrm{C}$ rectal temperature. The trachea was intubated to ensure an open airway, and the right carotid artery was cannulated to acquire MAP. PowerLab830 (AD Instruments) was used to record MAP. 


\section{Wire Myography Arterial Ring Preparation}

The thoracic aorta, common femoral artery, and third-order mesenteric arterioles were dissected and immediately placed in ice cold Ringer's solution. Two- to three-mm segments were cut and mounted in each wire myograph chamber (AD InstrumentsDMT $620 \mathrm{M}$ ) containing $5 \mathrm{~mL}$ of physiological salt solution (PSS; $119 \mathrm{mM} \mathrm{NaCl}, 4.7 \mathrm{mM} \mathrm{KCl}, 1.18 \mathrm{mM} \mathrm{KH}_{2} \mathrm{PO}_{4}, 1.17 \mathrm{mM}$ $\mathrm{MgSO}_{4}, 2.5 \mathrm{mM} \mathrm{CaCl}_{2}, 25 \mathrm{mM} \mathrm{NaHCO}_{3}, 0.027 \mathrm{mM}$ EDTA, and $5.5 \mathrm{mM}$ glucose) at $\mathrm{pH} 7.4$ and bubbled with $95 \% \mathrm{O}_{2} / 5 \% \mathrm{CO}_{2}$ at $37^{\circ} \mathrm{C}$. After $30 \mathrm{~min}$ of equilibration, maximum contractile response was determined by using high-potassium PSS (K + PSS; $123.7 \mathrm{mM} \mathrm{KCl}, 1.18 \mathrm{mM} \mathrm{KH}_{2} \mathrm{PO}_{4}, 1.17 \mathrm{mM} \mathrm{MgSO}$, $2.5 \mathrm{mM}$ $\mathrm{CaCl}_{2}, 25 \mathrm{mM} \mathrm{NaHCO}_{3}, 0.027 \mathrm{mM}$ EDTA, and $5.5 \mathrm{mM}$ glucose). Vessels were then washed twice with PSS and allowed to relax until initial tension was reached. Contractile responses were determined via cumulative additions of $50 \mu \mathrm{L}$ of phenylephrine $\left(\mathrm{PE} ; 1 \times 10^{-9}\right.$ to $\left.1 \times 10^{-4} \mathrm{M}\right)$. Relaxation responses were evaluated via cumulative addition of $50 \mu \mathrm{L}$ acetylcholine $(\mathrm{ACh})$ or sodium nitroprusside (SNP) $\left(1 \times 10^{-9}\right.$ to $\left.1 \times 10^{-4} \mathrm{M}\right)$.

\section{Statistics}

Point-to-point differences in the dose-response curves were evaluated using two-way repeated measures analysis of variance (ANOVA) with a Tukey's post hoc analysis when significance was found. The slopes of the dose-response curves were determined through non-linear regression. The animal characteristics, vessel characteristics, and dose-response curve slopes were analyzed using a one-way ANOVA with a Tukey's post hoc analysis when significance was found. All statistical analysis was completed with GraphPad Prism 5 (San Diego, CA, USA) and Sigma Plot 11.0 (San Jose, CA, USA). Significance was set at $P<0.05$, $n$ is the number of arterioles, and $N$ is the number of animals.

\section{Wire Myography Calculations}

Maximum tension was defined as the tension developed by the vessels with $\mathrm{K}+\mathrm{PSS}$. Tension with agonists (ACh, SNP, or PE) was recorded, and the percentage of maximum tension generation was calculated using the following formula:

$$
\begin{aligned}
& \text { Percentage maximum tension }(\%) \\
& =\left(\frac{\text { Tension with agonists }(\mathrm{mN})}{\text { Maximum tension }(\mathrm{mN})}\right) \times 100 \% .
\end{aligned}
$$

The response of the different arterial branching orders was quantitatively assessed and compared by using the slope of the individual dose-response curves as previously reported (31).

\section{Pressure Myography Arteriolar Preparation}

The mesentery was excised and placed in a dissecting dish with PSS maintained at $4^{\circ} \mathrm{C}$. Fourth- and fifth-order mesenteric arterioles were isolated, transferred to a vessel chamber, cannulated between two glass pipettes (outer diameter $60 \mu \mathrm{m}$ ), and secured by means of silk sutures in the vessel chamber (Living Systems Instrumentation, Burlington, VT, USA). The chamber was superfused with fresh oxygenated $\left(5 \% \mathrm{CO}_{2} / 21 \% \mathrm{O}_{2}\right)$ PSS and warmed to $37^{\circ} \mathrm{C}$. Arterioles were pressurized to $60 \mathrm{mmHg}$ using a servo control system and extended to their in situ length. Internal and external arteriolar diameters were measured using video calipers (Colorado Video, Boulder, CO, USA).

\section{Arteriolar Reactivity}

Arterioles were equilibrated for $1 \mathrm{~h}$ prior to experimentation. Arterioles with $<20 \%$ spontaneous tone were not analyzed. Contractile responses were determined via cumulative additions of $50 \mu \mathrm{L}$ of $\mathrm{PE}\left(1 \times 10^{-9}\right.$ to $\left.1 \times 10^{-4} \mathrm{M}\right)$. Relaxation responses were evaluated via cumulative addition of $50 \mu \mathrm{L}$ ACh or sodium nitroprusside $(\mathrm{SNP})\left(1 \times 10^{-9}\right.$ to $\left.1 \times 10^{-4} \mathrm{M}\right)$. The steady-state diameter of the vessel was recorded for at least 2 min after each dose. After each dose curve was completed, the vessel chamber was washed to remove excess chemicals by carefully removing the superfusate and replacing it with fresh warmed oxygenated PSS. After all experimental treatments were completed, the PSS was replaced with $\mathrm{Ca}^{2+}$-free PSS until maximum passive diameter was established.

\section{Pressure Myography Calculations}

All measurements were conducted during steady-state conditions, with steady state being defined as the interval during which blood vessels maintained a stable tone for $1 \mathrm{~min}$ or more. Vessels were washed twice with PSS between individual dose-response treatments and allowed approximately $10 \mathrm{~min}$ for equilibration or until original tone was developed. Data are expressed as means \pm SE. Spontaneous tone was calculated by the following equation:

$$
\text { Spontaneous tone }(\%)=\left\{\frac{\left(D_{\mathrm{m}}-D_{\mathrm{i}}\right)}{D_{\mathrm{i}}}\right\} \times 100,
$$

where $D_{\mathrm{m}}$ is the maximal diameter and $D_{\mathrm{i}}$ is the initial steady-state diameter recorded prior to the experiment. Active responses to pressure were normalized to the maximal diameter using the following formula:

$$
\text { Normalized diameter }=D_{\mathrm{ss}} / D_{\mathrm{m}},
$$

where $D_{\text {ss }}$ is the steady-state diameter recorded during each pressure change. The experimental responses to ACh and SNP are expressed using the following equation:

Diameter (percent maximal diameter $)=\left\{\frac{\left(D_{\mathrm{ss}}-D_{\text {con }}\right)}{\left(D_{\mathrm{m}}-D_{\text {con }}\right)}\right\} \times 100$,

where $D_{\text {Con }}$ is the control diameter recorded prior to the dose curve and $D_{\mathrm{SS}}$ is the steady-state diameter at each dose of the curve. The experimental response to $\mathrm{PE}$ is expressed using the following equation:

$$
\text { Diameter (percent maximal diameter })=\left\{\frac{\left(D_{\text {con }}-D_{\text {ss }}\right)}{\left(D_{\text {con }}\right)}\right\} \times 100 \text {. }
$$

Wall thickness was calculated from the measurement of both inner (ID) and outer (OD) steady-state arteriolar diameters at the end of the $\mathrm{Ca}^{2+}$-free wash using the following equation:

$$
\mathrm{WT}=(\mathrm{OD}-\mathrm{ID}) / 2 \text {. }
$$


Wall-to-lumen ratio was calculated using the following equation:

$$
\mathrm{WLR}=\mathrm{WT} / \mathrm{ID}
$$

\section{RESULTS}

\section{Animal and Vessel Characteristics}

No significant changes were observed in age, MAP, heart rate, and body weight between control and exposure groups (Table 1). Active inner diameter of fourth and fifth order mesenteric arterioles exposed to $200 \mu \mathrm{g}$ of nano- $\mathrm{TiO}_{2}(134.3 \pm 11 \mu \mathrm{m})$ and $100 \mu \mathrm{g}$ of nano- $\mathrm{TiO}_{2}(128.3 \pm 19 \mu \mathrm{m})$ were significantly different from control values $(115.4 \pm 10 \mu \mathrm{m})$, while passive diameter remained unchanged. This increase in diameter was associated with a decreased initial vascular tone (Table 2).

\section{Endothelium-Dependent Reactivity}

Two hundred micrograms of nano- $\mathrm{TiO}_{2}$ significantly impaired endothelium-dependent relaxation of thoracic aorta (Figure 1A) with a mean decrease in response to ACh of $53.96 \pm 11.6 \%$. No significant effects were seen at 100 and $20 \mu \mathrm{g}$ of nano- $\mathrm{TiO}_{2}$ (Figure 1A).

Femoral arteries from exposed animals showed a reduced cholinergic response solely at the lowest exposure concentration $\left(20 \mu\right.$ g nano- $\mathrm{TiO}_{2} / 250 \mu \mathrm{L}$ of vehicle) of $25.08 \pm 6.36 \%$ (Figure 1B). Further, 100 and $20 \mu \mathrm{g}$ nano- $\mathrm{TiO}_{2}$ exposure resulted in a mean reduction in relaxation of third-order mesenteric arterioles of $50.12 \pm 8.7$ and $68.28 \pm 8.7 \%$, respectively (Figure 1C). Finally, cholinergic reactivity of fourth- and fifth-order mesenteric arterioles was negatively affected by nano- $\mathrm{TiO}_{2}$ with diminished dilations of $82.86 \pm 12.6 \%$ after exposure to $200 \mu \mathrm{g}$ nano- $\mathrm{TiO}_{2}$, $42.6 \pm 12.6 \%$ after $100 \mu \mathrm{g}$ nano- $\mathrm{TiO}_{2}$, and $49.4 \pm 12.6 \%$ after $20 \mu \mathrm{g}$ nano- $\mathrm{TiO}_{2}$ (Figure 1D).
To consider the fullest scope of the biological response across the discrete entities of the vasculature, the slope of the individual dose-response curves was utilized as a means of numerically quantifying vascular reactivity (Figure 2) as previously shown $(7,31)$. Exposure to $200 \mu \mathrm{g}$ of nano- $\mathrm{TiO}_{2}$ decreased sensitivity to ACh from $16.29 \pm 1.2$ to $3.99 \pm 1.1 \mathrm{M}^{-1}$. Similarly, vascular reactivity of femoral arteries was diminished from the control value of $12.43 \pm 1.7$ to $7.77 \pm 3.6 \mathrm{M}^{-1}$ and $7.44 \pm 3.1 \mathrm{M}^{-1}$ with 200 and $100 \mu \mathrm{g}$ nano- $\mathrm{TiO}_{2}$, respectively. Third-order mesenteric arterioles showed a dose-dependent reduction in ACh sensitivity from control levels $\left(16.76 \pm 2.9 \mathrm{M}^{-1}\right)$ with $100 \mu \mathrm{g}$ nano- $\mathrm{TiO}_{2}$ having the greatest deleterious effect $\left(2.98 \pm 1.3 \mathrm{M}^{-1}\right)$, while 200 and $20 \mu \mathrm{g}$ nano- $\mathrm{TiO}_{2}$ reduced responsiveness to $6.93 \pm 3.2$ and $3.46 \pm 0.99 \mathrm{M}^{-1}$, respectively. Fourth- and fifth-order mesenteric arterioles showed the greatest decrease in vascular reactivity from controls $\left(14.73 \pm 1.5 \mathrm{M}^{-1}\right)$ particularly with $200 \mu \mathrm{g}$ nano- $\mathrm{TiO}_{2}\left(-11.46 \pm 5.1 \mathrm{M}^{-1}\right)$ and $20 \mu \mathrm{g}$ nano- $\mathrm{TiO}_{2}$ $\left(-1.55 \pm 0.8 \mathrm{M}^{-1}\right)$, while vessels exposed to $100 \mu \mathrm{g}$ nano- $\mathrm{TiO}_{2}$ showed slight ACh sensitivity $\left(1.15 \pm 0.4 \mathrm{M}^{-1}\right)$. These results provide additional evidence of an endothelium-dependent effect associated with nanomaterial exposure. The heterogeneity in impairment across the vasculature indicates the microcirculation as the prime site where these effects are most markedly manifest.

\section{$\alpha$-Adrenergic Sensitivity}

In contrast to endothelium-dependent relaxation, no pointto-point differences were seen in $\alpha$-adrenergic responses across all levels of the vasculature between nano- $\mathrm{TiO}_{2}$-exposed and control groups (Figures 3A-D). However, slope analysis, wherein the entire continuum of the vascular PE responses is assessed, revealed significant differences in vascular sensitivity induced by nano- $\mathrm{TiO}_{2}$ (Figure 4). Aortic PE sensitivity was increased by exposure to $100 \mu \mathrm{g}$ nano- $\mathrm{TiO}_{2}\left(11.2 \pm 1.3 \mathrm{M}^{-1}\right)$ with respect

TABLE 1 | Animal characteristics.

\begin{tabular}{|c|c|c|c|c|c|}
\hline Treatment & Number of rats $(N)$ & Age (weeks) & Body weight (g) & Mean arterial pressure $(\mathrm{mmHg})$ & Heart rate (bpm) \\
\hline Sham control & 16 & $8.5 \pm 0.2$ & $288 \pm 18$ & $90 \pm 4$ & $336 \pm 18$ \\
\hline Nano- $\mathrm{TiO}_{2} 200 \mu \mathrm{g}$ & 17 & $9.3 \pm 0.4$ & $295 \pm 18$ & $94 \pm 4$ & $330 \pm 8$ \\
\hline Nano- $\mathrm{TiO}_{2} 100 \mu \mathrm{g}$ & 16 & $9.5 \pm 0.1$ & $319 \pm 10$ & $82 \pm 3$ & $323 \pm 10$ \\
\hline Nano- $\mathrm{TiO}_{2} 20 \mu \mathrm{g}$ & 12 & $9.4 \pm 1.5$ & $322 \pm 19$ & $87 \pm 3$ & $311 \pm 16$ \\
\hline
\end{tabular}

Physical characteristics of control and exposed rats are listed. Values are shown as mean $\pm S E M$. Statistics were analyzed with two-way analysis of variance ( $P \leq 0.05)$. $N$, number of animals.

TABLE 2 | Arteriolar characteristics.

\begin{tabular}{|c|c|c|c|c|c|c|c|c|c|}
\hline & $n$ & $\begin{array}{l}\text { Inner diameter } \\
(\mu \mathrm{m})\end{array}$ & $\begin{array}{l}\text { Outer diameter } \\
\qquad(\mu \mathrm{m})\end{array}$ & $\begin{array}{l}\text { Tone } \\
(\%)\end{array}$ & $\begin{array}{c}\text { Passive diameter } \\
\text { inner }(\mu \mathrm{m})\end{array}$ & $\begin{array}{c}\text { Passive diameter } \\
\text { outer }(\mu \mathrm{m})\end{array}$ & $\begin{array}{l}\text { Wall thickness } \\
\qquad(\mu \mathrm{m})\end{array}$ & $\begin{array}{l}\text { Wall-to-lumen } \\
\text { ratio }\end{array}$ & $\begin{array}{l}\text { Wall tension } \\
\qquad\left(\mathrm{N} \mathrm{m}^{-1}\right)\end{array}$ \\
\hline Sham control & 11 & $115.4 \pm 10$ & $139.4 \pm 17$ & $31.2 \pm 7$ & $183.6 \pm 11$ & $152 \pm 8$ & $16 \pm 3$ & $0.104 \pm 0.03$ & $0.61 \pm 0.2$ \\
\hline Nano- $\mathrm{TiO}_{2} 200 \mu \mathrm{g}$ & 10 & $134.3 \pm 11^{*}$ & $146.2 \pm 15$ & $22.4 \pm 4^{*}$ & $187 \pm 20$ & $153.7 \pm 19$ & $17 \pm 1$ & $0.108 \pm 0.02$ & $0.62 \pm 0.1$ \\
\hline Nano- $\mathrm{TiO}_{2} 100 \mu \mathrm{g}$ & 9 & $128 \pm 19^{\star}$ & $144.6 \pm 24$ & $23.5 \pm 1^{*}$ & $182.5 \pm 11$ & $148.7 \pm 10$ & $17 \pm 3$ & $0.11 \pm 0.02$ & $0.6 \pm 0.3$ \\
\hline Nano- $\mathrm{TiO}_{2} 20 \mu \mathrm{g}$ & 10 & $110.7 \pm 12$ & $145.9 \pm 12$ & $20.3 \pm 3$ & $180.4 \pm 16$ & $152.6 \pm 14$ & $14 \pm 2$ & $0.09 \pm 0.03$ & $0.61 \pm 0.1$ \\
\hline
\end{tabular}

Fourth- and fifth-order mesenteric arterioles characteristics are shown. Values are shown as mean \pm SEM. Statistics were analyzed with two-way analysis of variance $(P \leq 0.05)$.

$n$, number of vessels.

${ }^{*} P \leq 0.05$ vs. sham control. 


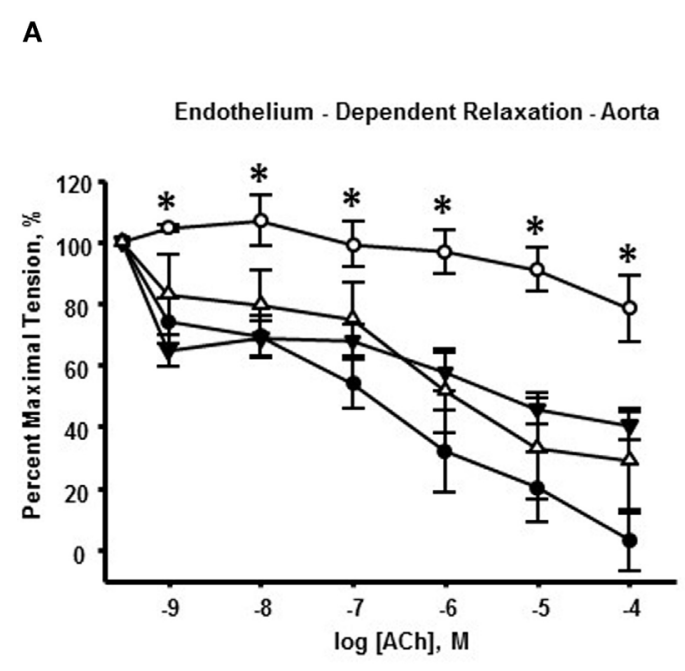

C

Endothelium - Dependent Relaxation - 3rd Order MA

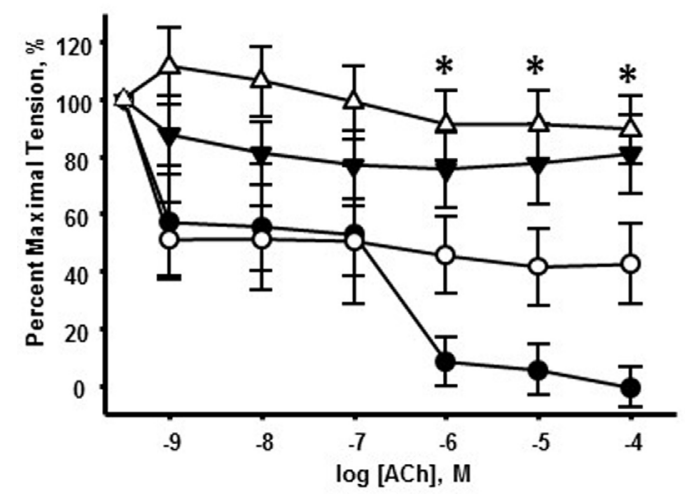

B

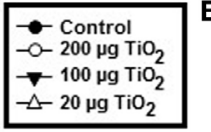

Endothelium - Dependent Relaxation - Femoral Artery

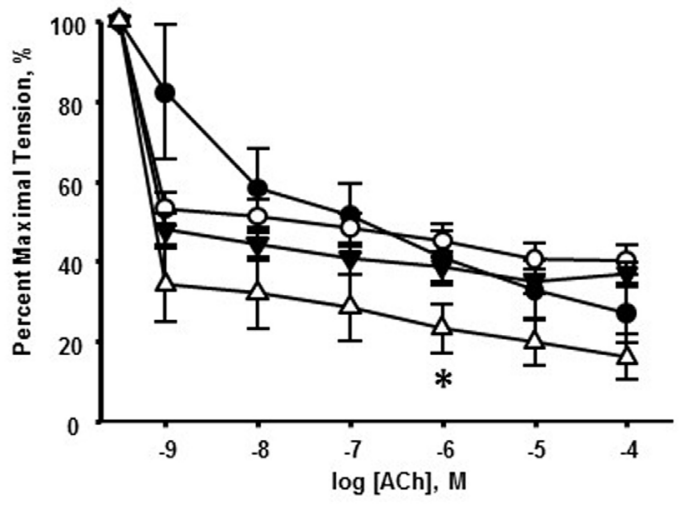

D

Endothelium - Dependent Relaxation - 4th/5th MA

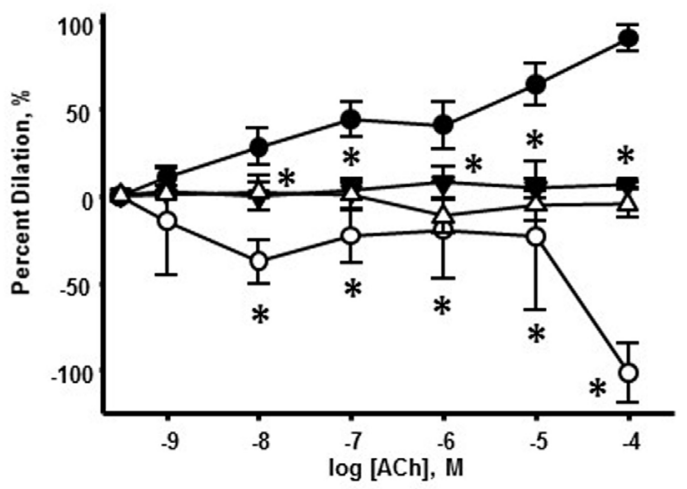

FIGURE 1 | Endothelium-dependent dilation is impaired by intratracheal instillation of nano-TiO ${ }_{2}$. acetylcholine (ACh)-induced vascular reactivity in (A) aorta, (B) femoral artery, (C) third-order mesenteric arterioles, and (D) fourth- and fifth-order mesenteric arterioles $(n=10-11)$. Statistics were analyzed with two-way analysis of variance (ANOVA) $(P \leq 0.05)$. *Sham control group vs. nano- $\mathrm{TiO}_{2}$-exposed groups.

to control values $\left(14.35 \pm 0.56 \mathrm{M}^{-1}\right)$. Significantly augmented adrenergic responses were seen in the femoral artery with $100\left(9.35 \pm 3.2 \mathrm{M}^{-1}\right)$ and $20 \mu \mathrm{g}$ nano- $\mathrm{TiO}_{2}\left(9.39 \pm 1.7 \mathrm{M}^{-1}\right)$ Also, $200 \mu \mathrm{g}$ nano- $\mathrm{TiO}_{2}\left(6.03 \pm 2 \mathrm{M}^{-1}\right)$ and $20 \mu \mathrm{g}$ nano- $\mathrm{TiO}_{2}$ $\left(6.36 \pm 1.4 \mathrm{M}^{-1}\right)$ caused increased vascular reactivity of third order mesenteric arterioles relative to controls $\left(1.95 \pm 2.7 \mathrm{M}^{-1}\right)$. Lastly, fourth and fifth mesenteric arterioles from exposed animals showed a clear proconstrictive effect particularly at $200 \mu \mathrm{g}$ nano- $\mathrm{TiO}_{2}\left(19.9 \pm 2 \mathrm{M}^{-1}\right)$ and $20 \mu \mathrm{g}\left(24.07 \pm 1.7 \mathrm{M}^{-1}\right)$, with $100 \mu \mathrm{g}\left(19.9 \pm 2 \mathrm{M}^{-1}\right)$ leading to responses similar to controls $\left(16.33 \pm 0.84 \mathrm{M}^{-1}\right)$ (Figure 4). This effect is consistent with previous work $(26,32)$ and confirms a potential effect on sympathetic tone, associated with ENM exposure.

\section{Endothelium-Independent Reactivity}

Endothelium-independent relaxation assessed via the spontaneous NO donor SNP was impaired in the thoracic aorta with a mean decrease in response of $34.05 \pm 25 \%$ induced by exposure to $200 \mu \mathrm{g}$ nano- $\mathrm{TiO}_{2}$ and a reduction in response of $49.31 \pm 25 \%$ caused by $100 \mu \mathrm{g}$ nano- $\mathrm{TiO}_{2}$ (Figure $\mathbf{5 A}$ ). Similarly, the response of the femoral artery to SNP was reduced by $18 \pm 5 \%$ (Figure 5B). Third-order mesenteric arterioles were negatively affected by $20 \mu \mathrm{g}$ nano- $\mathrm{TiO}_{2}$ with a mean decrease in response of $38.37 \pm 10 \%$ (Figure 5C). It is interesting to note that slope analysis demonstrated a decrease in SNP sensitivity only in thoracic aorta at $200 \mu \mathrm{g}$ $\left(21.28 \pm 2.03 \mathrm{M}^{-1}\right)$ and $100 \mu \mathrm{g}\left(18.91 \pm 2.1 \mathrm{M}^{-1}\right)$ nano- $\mathrm{TiO}_{2}$ compared to control $\left(26.46 \pm 3.08 \mathrm{M}^{-1}\right)$ (Figure 6). Similarly, fourth- and fifth-order mesenteric arteriolar sensitivity to SNP was significantly reduced from $\left(18.13 \pm 1.6 \mathrm{M}^{-1}\right)$ to $\left(15.99 \pm 1.79 \mathrm{M}^{-1}\right)$ by exposure to $20 \mu \mathrm{g}$ nano- $\mathrm{TiO}_{2}$. This is consistent with previous findings where impairments in endothelium-independent dilation in the microcirculation are not noted (33-35). 


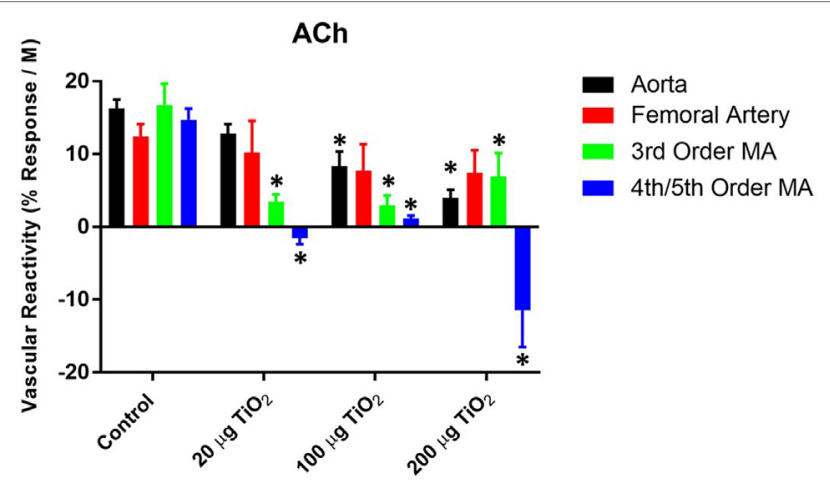

FIGURE 2 | Acetylcholine (ACh) sensitivity and vascular reactivity are decreased by nano- $\mathrm{TiO}_{2}$ exposure. Bar graphs showing the individual slope values for sham control and exposed vessels $(n=9-11)$. Statistics were analyzed with two-way analysis of variance $(P \leq 0.05)$. *Sham control group vs. nano- $\mathrm{TiO}_{2}$-exposed groups.

\section{DISCUSSION}

This is the first study to directly compare the differential effect of ENM exposure on discrete anatomical segments of the vascular tree. Pulmonary ENM exposure produced macrovascular and microvascular dysfunction resulting in impaired responses to endothelium-dependent, endothelium-independent, and adrenergic agonists. The major finding of this article is that acute nano$\mathrm{TiO}_{2}$ pulmonary exposure results in a more robust dysfunction at the microvascular level, and this is not simply because arterioles possess greater reactivity than arteries.

The microcirculation is critical in the regulation of the vascular internal environment for the controlled exchange of nutrients and metabolic waste with the adjacent tissues. Specifically, arterioles are major hemodynamic regulators and key players in the maintenance of blood pressure and flow distribution $(13,14)$. Disruptions in microvascular function are commonly associated with health consequences such as
A

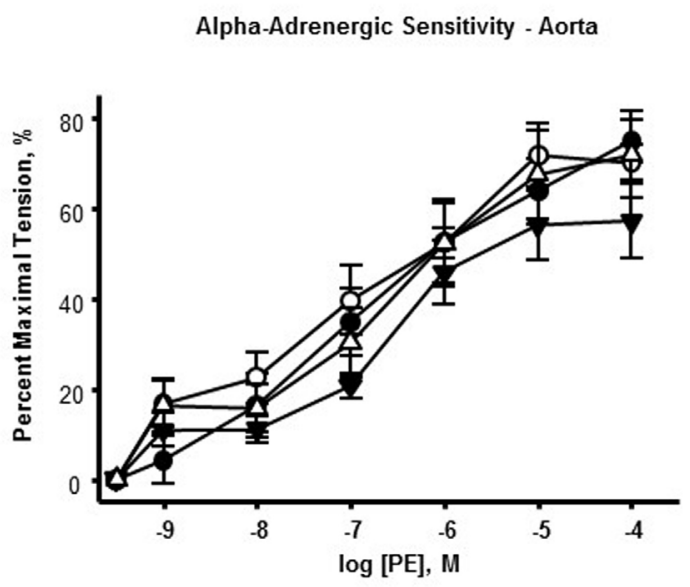

C

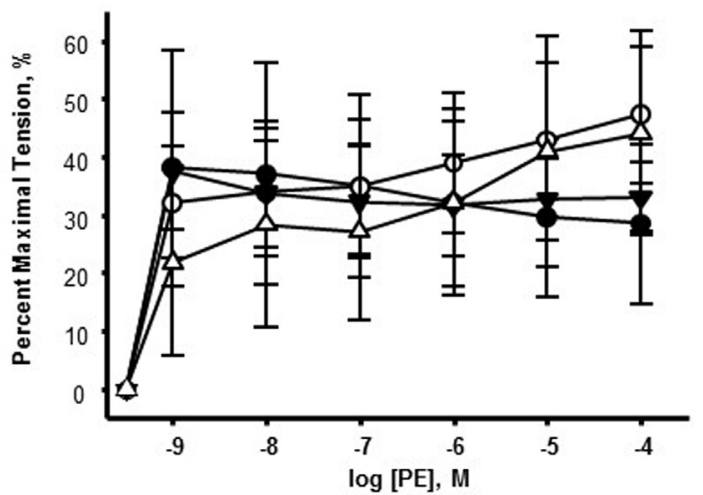

B $\bullet$ Control
$-200 \mu \mathrm{TiO}_{2}$
$-100 \mu \mathrm{TiO}_{2}$
$-20 \mu \mathrm{g} \mathrm{TiO}$
2

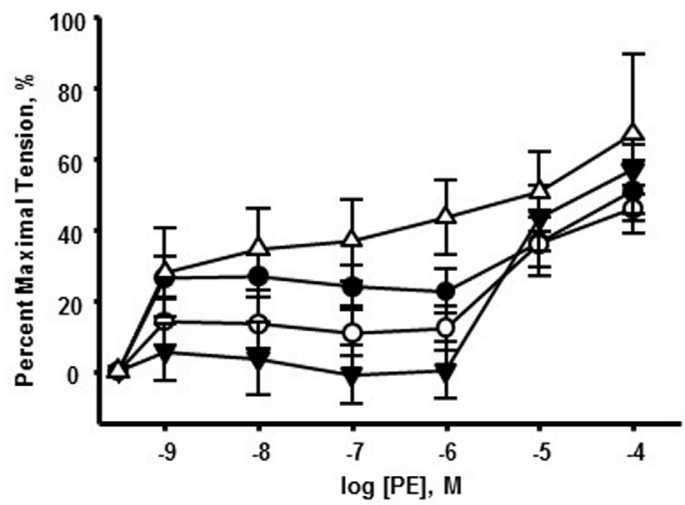

D Alpha-Adrenergic Sensitivity - 4th/5th MA

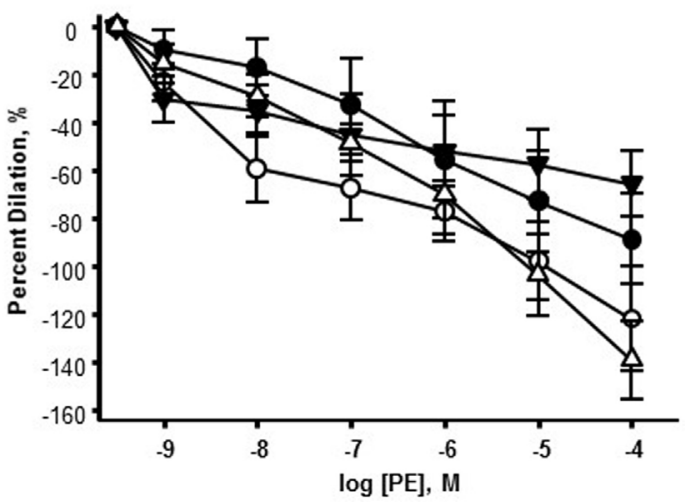

FIGURE 3 | $\boldsymbol{\alpha}$-adrenergic response to phenylephrine (PE) is not affected by nano-TiO ${ }_{2}$. PE response in (A) aorta, (B) femoral artery, (C) third order mesenteric arterioles, and (D) fourth and fifth mesenteric arterioles $(n=10-11)$. Statistics were analyzed with two-way analysis of variance (ANOVA) $(P \leq 0.05)$. 


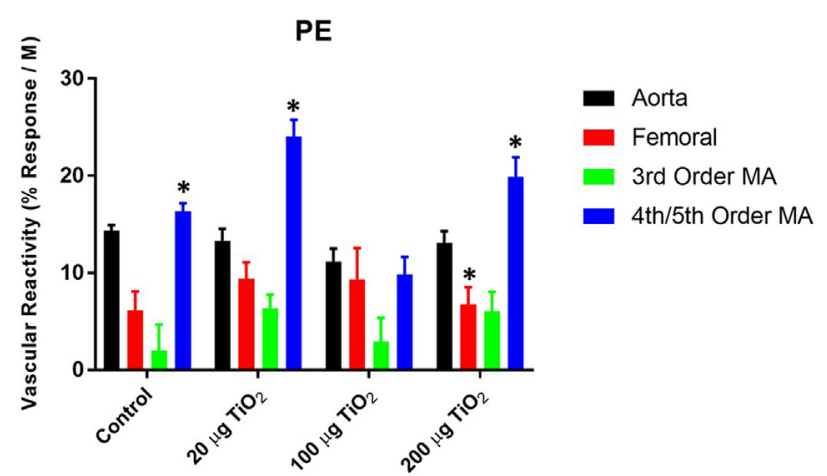

FIGURE 4 | Phenylephrine (PE) sensitivity are augmented by nano- $\mathrm{TiO}_{2}$ exposure. Bar graphs showing the individual slope values for sham control and exposed vessels $(n=10-11)$. Statistics were analyzed with two-way analysis of variance (ANOVA) $(P \leq 0.05)$. *Sham control group vs. nano- $\mathrm{TiO}_{2}$-exposed groups. hypertension and diabetes, and this is largely due to endothelial dysfunction (36).

The pronounced effect of ENM exposure on the microcirculation may be due to the propensity of nanoparticles to accumulate preferentially in this vascular compartment. Considerable evidence exists suggesting that after the initial exposure, nanomaterials tend to translocate and accumulate systemically $(37,38)$. Due to the existing hydrodynamic influences present within the microcirculation, it has been hypothesized that ENM deposition would likely be highest in the arterioles (39). Within arterioles, ENM may directly impair vascular function via generation of free radicals, decreasing NO bioavailability, NO synthase uncoupling, or by altering sympathetic tone.

Cholinergic activity was assessed using ACh. In normal conditions, ACh activates endothelial NO synthase (eNOS) by stimulating the release of intracellular calcium. L-Arginine is converted to L-citrulline by eNOS with the production of NO. eNOS requires a number of cofactors, including NADPH,
A

Endothelium-Independent Relaxation - Aorta

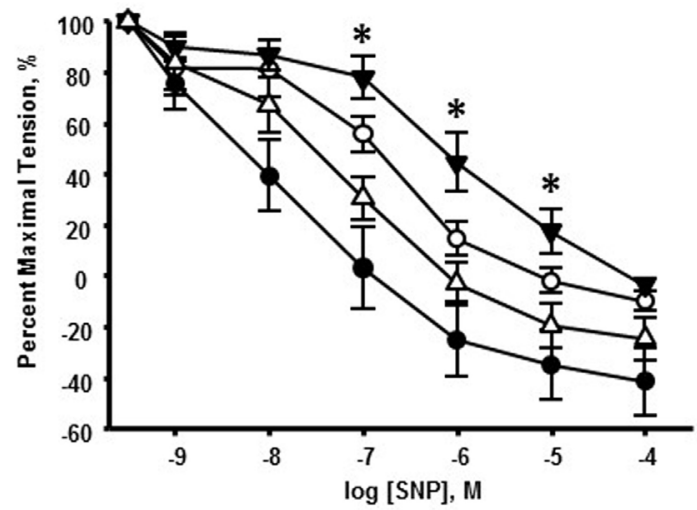

C Endothelium-Independent Relaxation - 3rd Order MA

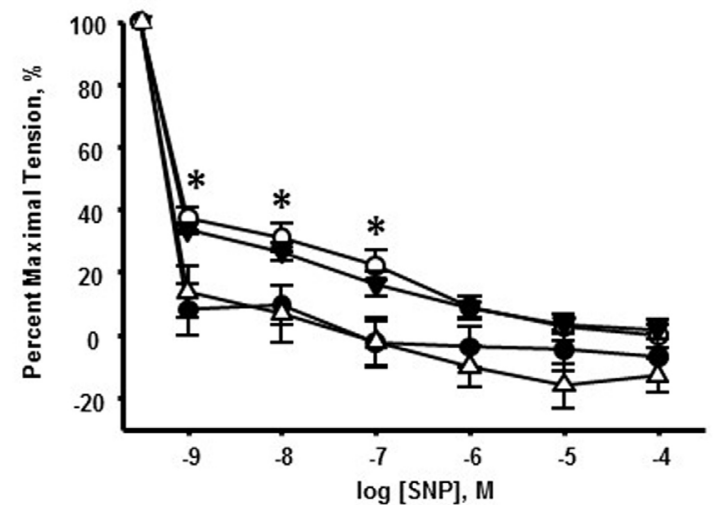

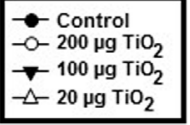

B

Endothelium-Independent Relaxation - Femoral Artery

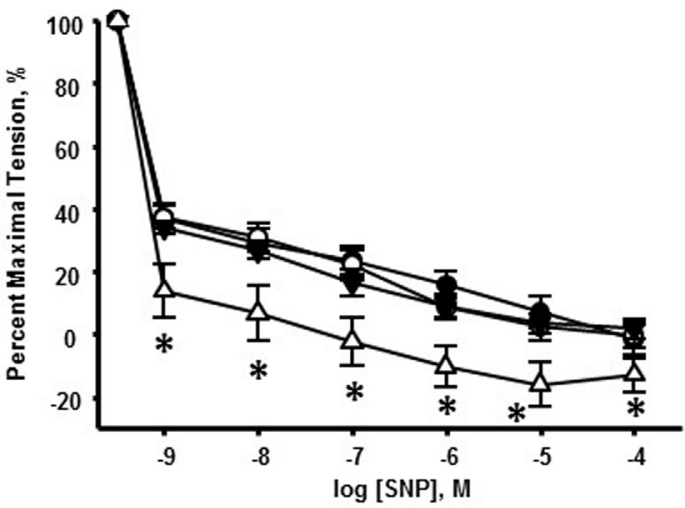

D

Endothelium-Independent Relaxation - 4th/5th MA

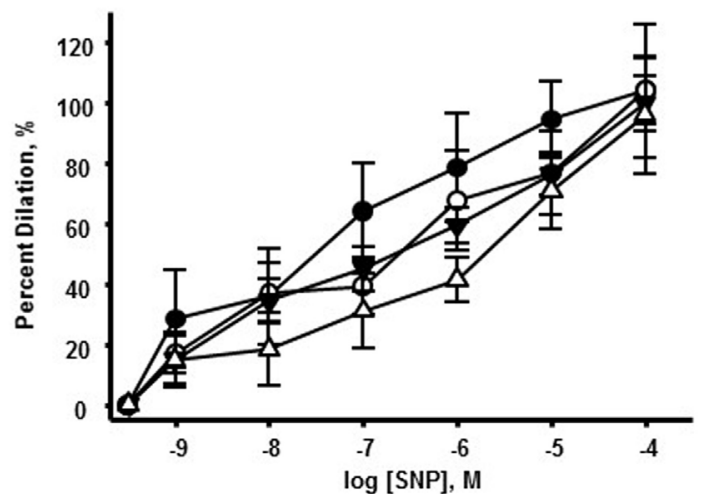

FIGURE 5 | Endothelium-independent dilation and vascular smooth muscle function is not impaired by nano-TiO ${ }_{2}$ exposure. Sodium nitroprusside (SNP) response in (A) aorta, (B) femoral artery, (C) third-order mesenteric arterioles, and (D) fourth- and fifth-order mesenteric arterioles $(n=10-11)$. Statistics were analyzed with two-way analysis of variance (ANOVA) $(P \leq 0.05)$. ${ }^{\star}$ Sham control group vs. nano-TiO ${ }_{2}$-exposed groups. 


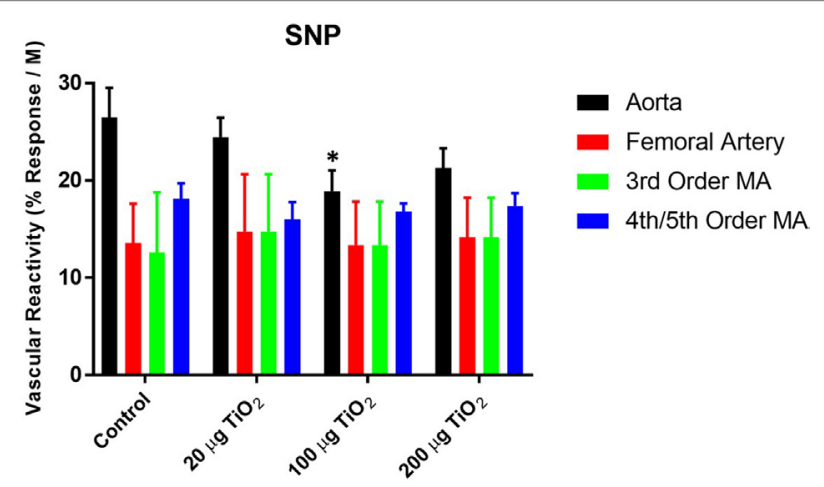

FIGURE 6 | Sodium nitroprusside (SNP)-induced vascular reactivity is unaffected by nano- $\mathrm{TiO}_{2}$ exposure. Bar graphs showing the individual slope values for sham control and exposed vessels $(n=10-11)$. Statistics were analyzed with two-way analysis of variance (ANOVA) $(P \leq 0.05)$. *Sham control group vs. nano- $\mathrm{TiO}_{2}$-exposed groups.

FAD, calcium, calmodulin, and $\mathrm{BH}_{4}$. $\mathrm{NO}$ subsequently diffuses into vascular smooth muscle cells and stimulates guanylate cyclase, ultimately resulting in cGMP production and vasodilation. In this study, reduced reactivity was seen in the thoracic aorta, femoral artery, third-order mesenteric arterioles and fourth-/fifth-order mesenteric arterioles. These effects are consistent with previous results obtained by our group and others $(32,40,41)$. It is interesting to note, however, that exposure to $200 \mu \mathrm{g}$ nano- $\mathrm{TiO}_{2}$ resulted in a complete reversal of the vasodilatory response by fourth-/fifth-order mesenteric arterioles, potentially indicating severe irreparable damage to the endothelial layer.

The endothelium is a major regulatory component common to all levels of the vasculature and plays a critical role in the control of vascular tone, the inflammatory response, maintenance and regulation of blood fluidity, permeability, and angiogenesis (42). Due to the significant role played in vascular homeostasis, it is becoming increasingly recognized that the endothelium is involved in most disease conditions, either as a primary determinant of pathophysiology or as a result of collateral damage (43).

No point-to-point impairments were seen in the response to the $\alpha$-adrenergic agonist PE. However, when considering the whole continuum of the vascular responses to this agonist, a prevalent increase in sensitivity, particularly at the microvascular level, was observed (Figure 4), consistent with previous work $(26,32)$.

Finally, endothelium-independent dysfunction was observed primarily in the macrocirculation, including the thoracic aorta, femoral artery, and third-order mesenteric arterioles (Figures 5 and 6). This differential effect on vascular smooth muscle response in the macrocirculation may be caused by the turbulent flow patterns characteristic of this segment, which contribute to an increased likelihood of deposition and impaction of ENM agglomerates particularly at large artery bifurcations (39).

Dysfunction in vascular smooth muscle following particulate matter exposure was first reported in pulmonary arteries by Courtois et al. (44). Previous work attributed this effect to a proinflammatory response triggered by particulate matter exposure, while other studies linked vascular dysfunction to an increase in oxidative stress (45).

Historically, the adverse systemic effects associated with pulmonary ENM exposure have been ascribed to a host inflammatory response, direct particle-tissue interactions, and/or autonomic dysregulation (3). The observed macrovascular and microvascular dysfunction could be associated with impaired NO production, a decrease in NO bioavailability caused by the generation of reactive oxygen species within the vascular wall, a shift in arachidonic acid metabolites, or vascular smooth muscle impairment or a combination of these mechanisms. It is outside the scope of this study to determine the mechanisms underlying the vascular endpoints herein reported, and future experiments are necessary to elucidate these mechanisms.

While the results of this study provide further indications of the microvascular effects associated with ENM, it is admittedly not without its limitations. Wire myography assesses the tension generated by vascular rings under isometric tension and therefore caution should be taken when interpreting the results obtained. This is particularly so for conduit arteries, in which changes in wall tension do not explicitly translate into vasomotion. Further, the use of in vitro techniques to evaluate vascular reactivity eliminates neurogenic and hormonal influences, which also play an important role in the mechanism of ENM cardiovascular toxicity. Therefore, future experiments utilizing ex vivo preparations (such as intravital microscopy) may be more appropriate to obtain a more thorough assessment.

\section{ETHICS STATEMENT}

All procedures were approved by the Institutional Animal Care and Use Committee of West Virginia University.

\section{AUTHOR CONTRIBUTIONS}

AA designed and performed the experiments, analyzed data, and wrote the paper; CM and JY provided technical support and edited the manuscript; TN and PS designed the experiments, supervised the study, and revised the manuscript.

\section{FUNDING}

This work was supported by the following sources: National Institutes of Health R01-ES015022 (TN), and K99-ES024783 (PS); the National Science Foundation Cooperative Agreement1003907 (TN and AA). 


\section{REFERENCES}

1. Borm P, Klaessig FC, Landry TD, Moudgil B, Pauluhn J, Thomas K, et al. Research strategies for safety evaluation of nanomaterials, part V: role of dissolution in biological fate and effects of nanoscale particles. Toxicol Sci (2006) 90:23-32. doi:10.1093/toxsci/kfj084

2. Nurkiewicz TR, Porter DW, Hubbs AF, Cumpston JL, Chen BT, Frazer DG, et al. Nanoparticle inhalation augments particle-dependent systemic microvascular dysfunction. Part Fibre Toxicol (2008) 5:1. doi:10.1186/1743-8977-5-1

3. Rajagopalan S, Brook RD. The indoor-outdoor air-pollution continuum and the burden of cardiovascular disease: an opportunity for improving global health. Glob Heart (2012) 7:207-13. doi:10.1016/j.gheart.2012.06.009

4. Mody VV, Siwale R, Singh A, Mody HR. Introduction to metallic nanoparticles. J Pharm Bioallied Sci (2010) 2:282-9. doi:10.4103/0975-7406.72127

5. Silva RM, Teesy C, Franzi L, Weir A, Westerhoff P, Evans JE, et al. Biological response to nano-scale titanium dioxide ( $\mathrm{TiO} 2)$ : role of particle dose, shape, and retention. J Toxicol Environ Health A (2013) 76:953-72. doi:10.1080/ 15287394.2013.826567

6. Weir A, Westerhoff P, Fabricius L, Hristovski K, von Goetz N. Titanium dioxide nanoparticles in food and personal care products. Environ Sci Technol (2012) 46:2242-50. doi:10.1021/es204168d

7. Palombo M, Deshmukh M, Myers D, Gao J, Szekely Z, Sinko PJ. Pharmaceutical and toxicological properties of engineered nanomaterials for drug delivery. Annu Rev Pharmacol Toxicol (2014) 54:581-98. doi:10.1146/ annurev-pharmtox-010611-134615

8. Bonner JC, Silva RM, Taylor AJ, Brown JM, Hilderbrand SC, Castranova V, et al. Interlaboratory evaluation of rodent pulmonary responses to engineered nanomaterials: the NIEHS Nano GO Consortium. Environ Health Perspect (2013) 121:676-82. doi:10.1289/ehp.1205693

9. Hougaard KS, Jackson P, Jensen KA, Sloth JJ, Löschner K, Larsen EH, et al. Effects of prenatal exposure to surface-coated nanosized titanium dioxide (UV-Titan). A study in mice. Part Fibre Toxicol (2010) 7:16. doi:10.1186/ 1743-8977-7-16

10. Warheit DB, Webb TR, Reed KL, Frerichs S, Sayes CM. Pulmonary toxicity study in rats with three forms of ultrafine- $\mathrm{TiO} 2$ particles: differential responses related to surface properties. Toxicology (2007) 230:90-104. doi:10.1016/j. tox.2006.11.002

11. Ma-Hock L, Burkhardt S, Strauss V, Gamer AO, Wiench K, van Ravenzwaay B, et al. Development of a short-term inhalation test in the rat using nanotitanium dioxide as a model substance. Inhal Toxicol (2009) 21:102-18. doi:10.1080/08958370802361057

12. Popel AS, Johnson PC. Microcirculation and hemorheology. Annu Rev Fluid Mech (2005) 37:43-69. doi:10.1146/annurev.fluid.37.042604.133933

13. Pries AR, Secomb TW. Rheology of the microcirculation. Clin Hemorheol Microcirc (2003) 29:143-8. doi:10.1080/10739680590894966

14. Pries AR, Secomb TW, Gaehtgens P. Biophysical aspects of blood flow in the microvasculature. Cardiovasc Res (1996) 32:654-67. doi:10.1016/ 0008-6363(96)00065-X

15. Michiels C. Endothelial cell functions. J Cell Physiol (2003) 196:430-43. doi:10.1002/jcp. 10333

16. Baldwin AL, Thurston G. Mechanics of endothelial cell architecture and vascular permeability. Crit Rev Biomed Eng (2001) 29:247-78. doi:10.1615/ CritRevBiomedEng.v29.i2.20

17. Cines DB. Glycoprotein IIb/IIIa antagonists: potential induction and detection of drug-dependent antiplatelet antibodies. Am Heart J (1998) 135:S152-9. doi:10.1016/S0002-8703(98)70243-1

18. Sadler JE. Thrombomodulin structure and function. Thromb Haemost (1997) 78:392-5.

19. Pearson JD, Carleton JS, Gordon JL. Metabolism of adenine nucleotides by ectoenzymes of vascular endothelial and smooth-muscle cells in culture. Biochem J (1980) 190:421-9. doi:10.1042/bj1900421

20. Muller WA. Leukocyte-endothelial cell interactions in the inflammatory response. Lab Invest (2002) 82:521-33. doi:10.1038/labinvest.3780446

21. Ellies LG, Sperandio M, Underhill GH, Yousif J, Smith M, Priatel JJ, et al. Sialyltransferase specificity in selectin ligand formation. Blood (2002) 100: 3618-25. doi:10.1182/blood-2002-04-1007

22. Forlow SB, Foley PL, Ley K. Severely reduced neutrophil adhesion and impaired host defense against fecal and commensal bacteria in CD18-/-P-selectin-/double null mice. FASEB J (2002) 16:1488-96. doi:10.1096/f.02-0230com
23. Schober A, Manka D, von Hundelshausen P, Huo Y, Hanrath P, Sarembock IJ, et al. Deposition of platelet RANTES triggering monocyte recruitment requires P-selectin and is involved in neointima formation after arterial injury. Circulation (2002) 106:1523-9. doi:10.1161/01.CIR.0000028590.02477.6F

24. Smith ML, Smith MJ, Lawrence MB, Ley K. Viscosity-independent velocity of neutrophils rolling on p-selectin in vitro or in vivo. Microcirculation (2002) 9:523-36. doi:10.1080/713774098

25. Aird WC. Mechanisms of endothelial cell heterogeneity in health and disease. Circ Res (2006) 98:159-62. doi:10.1161/01.RES.0000204553.32549.a7

26. Knuckles TL, Yi J, Frazer DG, Leonard HD, Chen BT, Castranova V, et al. Nanoparticle inhalation alters systemic arteriolar vasoreactivity through sympathetic and cyclooxygenase-mediated pathways. Nanotoxicology (2012) 6:724-35. doi:10.3109/17435390.2011.606926

27. Minarchick VC, Stapleton PA, Porter DW, Wolfarth MG, Çiftyürek E, Barger $\mathrm{M}$, et al. Pulmonary cerium dioxide nanoparticle exposure differentially impairs coronary and mesenteric arteriolar reactivity. Cardiovasc Toxicol (2013) 13:323-37. doi:10.1007/s12012-013-9213-3

28. Stapleton PA, McBride CR, Yi J, Nurkiewicz TR. Uterine microvascular sensitivity to nanomaterial inhalation: an in vivo assessment. Toxicol Appl Pharmacol (2015) 288:420-8. doi:10.1016/j.taap.2015.08.013

29. Sager TM, Castranova V. Surface area of particle administered versus mass in determining the pulmonary toxicity of ultrafine and fine carbon black: comparison to ultrafine titanium dioxide. Part Fibre Toxicol (2009) 6:15. doi:10.1186/1743-8977-6-15

30. Sager TM, Kommineni C, Castranova V. Pulmonary response to intratracheal instillation of ultrafine versus fine titanium dioxide: role of particle surface area. Part Fibre Toxicol (2008) 5:17. doi:10.1186/1743-8977-5-17

31. Wright CE, Angus JA. Effects of hypertension and hypercholesterolemia on vasodilatation in the rabbit. Hypertension (1986) 8:361-71. doi:10.1161/01. HYP.8.5.361

32. Vidanapathirana AK, Thompson LC, Mann EE, Odom JT, Holland NA, Sumner SJ, et al. PVP formulated fullerene (C60) increases Rho-kinase dependent vascular tissue contractility in pregnant Sprague Dawley rats. Reprod Toxicol (2014) 49:86-100. doi:10.1016/j.reprotox.2014.07.074

33. LeBlanc AJ, Cumpston JL, Chen BT, Frazer D, Castranova V, Nurkiewicz TR. Nanoparticle inhalation impairs endothelium-dependent vasodilation in subepicardial arterioles. J Toxicol Environ Health A (2009) 72:1576-84. doi:10.1080/15287390903232467

34. Nurkiewicz TR, Porter DW, Barger M, Castranova V, Boegehold MA. Particulate matter exposure impairs systemic microvascular endothelium-dependent dilation. Environ Health Perspect (2004) 112:1299-306. doi:10.1289/ehp.7001

35. Stapleton PA, Minarchick VC, Cumpston AM, McKinney W, Chen BT, Sager TM, et al. Impairment of coronary arteriolar endothelium-dependent dilation after multi-walled carbon nanotube inhalation: a time-course study. Int J Mol Sci (2012) 13:13781-803. doi:10.3390/ijms131113781

36. Schwartzkopff B, Mundhenke M, Strauer BE. Alterations of the architecture of subendocardial arterioles in patients with hypertrophic cardiomyopathy and impaired coronary vasodilator reserve: a possible cause for myocardial ischemia. J Am Coll Cardiol (1998) 31:1089-96. doi:10.1016/S0735-1097 (98)00036-9

37. Mercer RR, Scabilloni JF, Hubbs AF, Battelli LA, McKinney W, Friend S, et al. Distribution and fibrotic response following inhalation exposure to multi-walled carbon nanotubes. Part Fibre Toxicol (2013) 10:33. doi:10.1186/1743-8977-10-33

38. Mercer RR, Scabilloni JF, Hubbs AF, Wang L, Battelli LA, McKinney W, et al. Extrapulmonary transport of MWCNT following inhalation exposure. Part Fibre Toxicol (2013) 10:38. doi:10.1186/1743-8977-10-38

39. Stapleton PA, Nurkiewicz TR. Vascular distribution of nanomaterials. Wiley Interdiscip Rev Nanomed Nanobiotechnol (2014) 6:338-48. doi:10.1002/ wnan. 1271

40. Nurkiewicz TR, Porter DW, Hubbs AF, Stone S, Chen BT, Frazer DG, et al. Pulmonary nanoparticle exposure disrupts systemic microvascular nitric oxide signaling. Toxicol Sci (2009) 110:191-203. doi:10.1093/toxsci/ kfp051

41. Stapleton PA, Nichols CE, Yi J, McBride CR, Minarchick VC, Shepherd DL, et al. Microvascular and mitochondrial dysfunction in the female F1 generation after gestational $\mathrm{TiO} 2$ nanoparticle exposure. Nanotoxicology (2015) 9:941-51. doi:10.3109/17435390.2014.984251

42. Aird WC. Endothelial cell heterogeneity. Cold Spring Harb Perspect Med (2012) 2:a006429. doi:10.1101/cshperspect.a006429 
43. Aird WC. Endothelial cell heterogeneity. Crit Care Med (2003) 31:S221-30. doi:10.1097/01.CCM.0000057847.32590.C1

44. Courtois A, Andujar P, Ladeiro Y, Baudrimont I, Delannoy E, Leblais V, et al. Impairment of NO-dependent relaxation in intralobar pulmonary arteries: comparison of urban particulate matter and manufactured nanoparticles. Environ Health Perspect (2008) 116:1294-9. doi:10.1289/ehp.11021

45. LeBlanc AJ, Moseley AM, Chen BT, Frazer D, Castranova V, Nurkiewicz TR. Nanoparticle inhalation impairs coronary microvascular reactivity via a local reactive oxygen species-dependent mechanism. Cardiovasc Toxicol (2010) 10:27-36. doi:10.1007/s12012-009-9060-4
Conflict of Interest Statement: The authors declare that the research was conducted in the absence of any commercial or financial relationships that could be construed as a potential conflict of interest.

Copyright ( 2017 Abukabda, Stapleton, McBride, Yi and Nurkiewicz. This is an open-access article distributed under the terms of the Creative Commons Attribution License (CC BY). The use, distribution or reproduction in other forums is permitted, provided the original author(s) or licensor are credited and that the original publication in this journal is cited, in accordance with accepted academic practice. No use, distribution or reproduction is permitted which does not comply with these terms. 